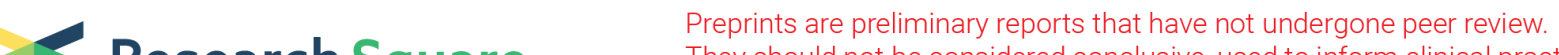 Research Square They should not be considered conclusive, used to inform clinical practice, or referenced by the media as validated information.
}

\section{Multimodality Imaging for Optimal Device-size Selection During Percutaneous Left Atrial Appendage Closure in Thai Population}

Sakolwat Montrivade ( $\nabla$ sakolmontri@hotmail.com )

King Chulalongkorn Memorial Hospital https://orcid.org/0000-0002-0006-3138

Vorarit Lertsuwunseri

King Chulalongkorn Memorial Hospital

Monravee Tumkosit

King Chulalongkorn Memorial Hospital

Suphot Srimahachota

Chulalongkorn University Faculty of Medicine

\section{Research Article}

Keywords: Percutaneous left atrial appendage closure, device-size, multi-detector CT scan, transesophageal echocardiography

Posted Date: March 8th, 2021

DOI: https://doi.org/10.21203/rs.3.rs-277441/v1

License: (9) This work is licensed under a Creative Commons Attribution 4.0 International License. Read Full License 


\section{Abstract}

Background: Optimal device size selection is crucial for percutaneous left atrial appendage (LAA) closure. Transesophageal echocardiography (TEE) is the standard imaging technique for LAA assessment, however there are discrepancies among different imaging modalities. We aimed to evaluate the agreement between device size and LAA size measured by three methods: multi-detector cardiac computed tomography (MDCT), TEE, and angiography.

Methods: Patients who underwent percutaneous LAA closure at King Chulalongkorn Memorial Hospital from 2012 to 2020 were included in this study. MDCT, TEE and angiography were reviewed. LAA ostial diameter, landing zone diameter and maximal depth from each imaging modality was measured and analyzed. Agreement between landing zone diameter and implanted device size was assessed.

Results: We reported on 61 consecutive patients who underwent percutaneous LAA closure. The mean age of patients was $74.0 \pm 8.4$ years. The mean $\mathrm{CHA}_{2} \mathrm{DS}_{2}$ score, $\mathrm{CHA}_{2} \mathrm{DS}_{2}-\mathrm{VASc}$ score and HAS-BLED score were $2.8 \pm 1.4,4.6 \pm 1.8$ and $2.6 \pm 1.0$, respectively. Device implantation was successful in all patients (100\%). Two different LAA closure devices were used: Watchman $(n=43,70.5 \%)$ and Omega (n $=18,29.5 \%$ ). Maximum landing zone diameter measured by MDCT scan, TEE and angiography were 23.4 $\pm 3.9 \mathrm{~mm}, 22.2 \pm 4.8 \mathrm{~mm}$ and $22.7 \pm 3.5 \mathrm{~mm}$, respectively. MDCT measurement was significantly larger than TEE measurement $(p=0.015)$ and closer to implanted device size compared with TEE and angiography. The difference between landing zone diameter measured by CT scan and device size was $-1.65 \pm 2.0 \mathrm{~mm}$ compared with $-4.8 \pm 4.6 \mathrm{~mm}$ for TEE and $-4.3 \pm 3.3 \mathrm{~mm}$ for angiography.

Conclusion: MDCT sizing of LAA results in larger measurement than TEE. Routine implementation of MDCT sizing may improve procedural success with more accurate device size selection.

\section{Introduction}

Percutaneous left atrial appendage (LAA) closure is an emerging alternative treatment for stroke prevention in patients with atrial fibrillation who are at increased risk of bleeding or contraindicated to oral anticoagulation.[1-5] Transesophageal echocardiography (TEE) is the standard imaging for LAA assessment for procedural planning and device size selection.[6-8] Appropriate device size is crucial in percutaneous LAA closure as under-sizing can lead to peri-device leakage and device embolization. Device over-sizing may also cause LAA perforation, pericardial effusion and cardiac tamponade.[8]

Evaluation of LAA by TEE is challenging due to complex anatomy and technical difficulties. Recent studies reported that LAA measurement using multi-detector cardiac computed tomography (MDCT) is more accurate compared to TEE and LAA angiography,[9-12] however, manufacturer recommendations for device size selection is currently based on TEE measurement. We aimed to evaluate the LAA size measured by TEE, MDCT and angiography, and study the agreement between LAA size from each imaging modality and the size of the successfully implanted LAA closure device. 


\section{Materials And Methods}

All patients who had atrial fibrillation and underwent percutaneous LAA closure at King Chulalongkorn Memorial Hospital between 2012 to 2020 were included in this study. Baseline patient characteristics, procedural records and post-procedural patient follow-up were collected from electronic medical records. Pre-procedural and intra-procedural TEE, pre-procedural CT and intra-procedural LAA angiography were reviewed and analyzed retrospectively by investigators. The study was conducted in accordance with the Institutional Human Subjects Committee guidelines and approved by the Institutional Review Board at Faculty of Medicine, Chulalongkorn University.

\section{Transesophageal echocardiography sizing of LAA}

Pre-procedural and intra-procedural two-dimensional (2D) TEE images were meticulously reviewed by investigators. TEE was performed with standard TEE transducer (Vivid, Philips, the Netherlands). TEE images of four standard planes $\left(0^{0}, 45^{0}, 90^{\circ}\right.$ and $\left.135^{\circ}\right)$ were identified for LAA sizing (Figure 1). The LAA ostium and landing zone were measured from all 4 TEE views: 1) maximal diameter of the LAA ostium, 2) maximal LAA depth measured from the LAA ostial plane to the LAA apex, 3) maximal diameter of the LAA landing zone which is measured from the circumflex coronary artery to a point $2 \mathrm{~cm}$ below the tip of the left upper pulmonary vein limbus for Watchman device and measured at 10 to $12 \mathrm{~mm}$ distal to the ostium at an angle perpendicular to the neck axis for Omega device, and 4) landing zone depth measured from the landing zone plane to the LAA apex for Watchman device and measured perpendicularly toward the back of LAA for Omega device. LAA morphology and the presence or absence of thrombus were also assessed by pre-procedural TEE.

\section{CT imaging and sizing of LAA}

Pre-procedure contrast-enhanced multi-detector CT (320-multidetector scanner, Aquilion One Vision Edition, Toshiba Medical Systems, Japan) was used to evaluate LAA. Retrospective ECG-gate for cardiac CT was performed. A volume of $50 \mathrm{ml}$ of contrast (lopomira $370 \mathrm{mgl} / \mathrm{mL}$ ) was delivered via the antecubital vein with $50 \mathrm{ml}$ saline flush at $5 \mathrm{ml} / \mathrm{s}$. Multi-planar reconstruction was used to obtain orthogonal views and oblique planes of the LAA. LAA size was measured with 4 dimensions: 1) maximal and minimal diameter of the LAA ostium, 2) maximal LAA depth measured from the LAA ostial plane to the LAA apex, 3) maximal and minimal diameter of the conventional landing zone $10 \mathrm{~mm}$ distal to the LAA ostium, and 4) maximal and minimal diameter of LAA at $12 \mathrm{~mm}$ and $15 \mathrm{~mm}$ distal to the LAA ostium (Figure 1).

\section{LAA angiography and sizing}

LAA angiography was performed at the time of procedure using pigtailed catheter. Two standard angiography views of LAA were included (RAO $30^{\circ}$ Cranial $10-20^{\circ}$ and RAO $30^{\circ}$ Caudal $10-20^{\circ}$ ). LAA sizing by angiography was measured with 4 dimensions: 1) maximal diameter of the LAA ostium; 2 ) maximal diameter at the landing zone $10-20 \mathrm{~mm}$ distal to the LAA ostium; 3) maximal LAA depth 
measured from the LAA ostial plane to the LAA apex, and 4) landing zone depth measured from the landing zone plane to the LAA apex.

\section{LAA closure procedure}

All LAA closure device implantations were performed by experienced interventional cardiologists via femoral venous access and local anesthesia with light sedation. Trans-septal puncture was achieved under TEE guidance. Unfractionated intravenous heparin was administered at a dose of $70 \mathrm{IU} / \mathrm{kg}$, target activated clotting time $>250$ seconds. The decision regarding final device size was based on preprocedural TEE, intra-procedural TEE, preprocedural CT and intra-procedural LAA angiography with reference to manufacturer's sizing guidelines. The position of the device, the presence of peri-device leak, and the degree of compression were assessed by TEE before device release and immediately after deployment. Left ventricular systolic function, pulmonary venous inflow, pericardium condition, inter-atrial septum and degree of mitral regurgitation were carefully assessed prior to procedural conclusion. Transthoracic echocardiography was performed before hospital discharge and TEE was conducted at 45 to 60 days post-procedure to assess peri-device leakage, device-related thrombosis, device position, pericardial effusion and other complications. Mild peri-device leakage was defined as a jet $<3 \mathrm{~mm}$ in diameter. Moderate and severe leakages was defined as jet diameters of 3 to $5 \mathrm{~mm}$ and $>5 \mathrm{~mm}$, respectively. The decision to maintain oral anticoagulation or antiplatelets was determined by the attending cardiologists. Patients were routinely followed for complications and cardiovascular events at 6 weeks, 3 months, 6 months, 1 year, and then annually or as appropriate.

\section{Comparison of LAA sizing among different imaging modalities}

LAA size measurements from pre-procedural TEE, pre-procedural CT and LAA angiography were compared in four ways: 1) maximal diameter of the LAA ostium, 2) maximal diameter at the landing zone, 3) maximal LAA depth, and 4) landing zone depth. Maximal diameter at the landing zone of each imaging modalities were also compared to the final device size that was successfully implanted and is considered to be the optimal device size for the individual patient in our study.

\section{Statistical analysis}

Continuous variables are reported as mean \pm SD and categorical variables are reported as counts and percentages. Continuous variables were compared using independent t-test and Mann-Whitney $\mathrm{U}$ test. Analysis of categorical variables employed the Chi-square test and Fisher's exact test. We investigated the agreement between maximal LAA landing zone diameter from each imaging modality and final implanted device size using adapted Bland-Altman plot into the LAA. The $95 \%$ limits of agreement (mean difference $\pm 2 \times S D$ ) were calculated for each imaging modality. A two-sided $p$ value $<0.05$ was considered statistically significant. Statistical analyses were performed with SPSS (SPSS version 23).

\section{Results}




\section{Patients characteristics}

A total of 61 patients were included in this study. The mean age was $74.0 \pm 8.4$ years with $26(42.6 \%)$ female patients. The mean $\mathrm{CHA}_{2} \mathrm{DS}_{2}$ score, $\mathrm{CHA}_{2} \mathrm{DS}_{2}$-VASc score and HAS-BLED score were $2.8 \pm 1.4,4.6$ \pm 1.8 and $2.6 \pm 1.0$, respectively. Important predictors of stroke including age $>75$ years, congestive heart failure, and previous stroke presented in $45.9 \%, 16.4 \%$, and $47.5 \%$ of patients, respectively. There were 31 patients $(50.8 \%)$ with a previous history of bleeding. Paroxysmal AF was found in $30(49.2 \%)$ patients and permanent $\mathrm{AF}$ in $31(50.8 \%)$ patients. Oral anticoagulation had been prescribed in $75.4 \%$ of patients, mainly warfarin (62.3\%). Baseline characteristics are summarized in Table 1.

\section{LAA closure procedural characteristics}

Device implantation was successful in all patients. Two different LAA closure devices were used: Watchman $(n=43,70.5 \%)$ and Omega $(n=18,29.5 \%)$. Median hospital length of stay was 1 day (interquartile range 1 to 2 ). All procedures were performed under local anesthesia with conscious sedation and TEE guidance. Mean numbers of attempts was $1.7 \pm 1.6$ times with 7 patients $(11.5 \%)$ needed to change device size. Mean procedural time was $51.1 \pm 24.4$ minutes. Mean fluoroscopy time was $7.7 \pm 6.0$ minutes.

The procedure was successful without peri-device leakage identified by TEE and angiogram in 57 patients (93.4\%) and successful with mild leakage in 4 patients (6.6\%). Final implanted device size was within manufacturer's recommendations in $42.1 \%$, oversized in $54.4 \%$ and undersized in $3.5 \%$ of all patients. There was no major leakage with any patient. Immediate complications were air embolism into right coronary artery $(n=1,1.6 \%)$ and pericardial effusion $(n=2,3.3 \%)$. Post procedural medications were oral anticoagulant for 6 weeks followed by dual antiplatelets for 6 months in $36.1 \%$, dual antiplatelets for 6 months followed by single aspirin therapy in $47.5 \%$ and extended dual antiplatelets in $13.1 \%$ with $3.3 \%$ not needing medications. LAA closure procedural characteristics were summarized in Table 2.

\section{Forty-five to sixty days TEE follow-up and long-term outcome}

At routine 45 to 60 day patient follow-up TEE, there were no leakage in $70.5 \%$, mild leakage in $26.2 \%$ and moderate leakage in $3.3 \%$. There was no difference in the severity of peri-device leakage among patients who had implanted device size within manufacturer's recommendation, oversized and undersized ( $p$ $=0.898)$, as shown in Table 3. There was pericardial effusion in 1 patient (1.6\%), device related thrombosis in 2 patients (3.3\%), LA thrombus in 1 patient (1.6\%) and device protrusion in 2 patients (3.3\%). Median duration of follow up was 14.7 months (IQR: 5.3-45.9 months). At long-term follow up, three patients $(4.9 \%)$ had recurrent stroke, two patients $(3.3 \%)$ had cardiovascular death and one patient $(1.6 \%)$ had pericardial effusion requiring pericardiocentesis.

\section{Comparison of LAA size and device size selection by different imaging modalities}


Pre-procedural, periprocedural and post-procedural TEE were completed in 57 (93.4\%) cases. All patients had angiographic assessment for LAA sizing. Only 18 patients (29.5\%) had undergone a pre-procedural CT scan. Maximum diameter of LAA ostium measured by TEE, CT scan and angiography were $24.1 \pm 6.1$ $\mathrm{mm}, 26.6 \pm 4.4 \mathrm{~mm}$, and $22.5 \pm 3.8 \mathrm{~mm}$, respectively. Maximum landing zone diameter measured by TEE, CT scan and angiography were $22.2 \pm 4.8 \mathrm{~mm}, 23.4 \pm 3.9 \mathrm{~mm}$ and $22.7 \pm 3.5 \mathrm{~mm}$, respectively. Both maximum diameter of LAA ostium and landing zone diameter were larger as measured by CT scan compared to TEE ( $p=0.025$ and $p=0.015)$.

Using the final implanted device size as an optimal size for comparison, the CT scan was closer to device size compared to TEE and angiography with a difference of $-1.65 \pm 2.0 \mathrm{~mm}$ between landing zone diameter as measured by CT scan and device size compared to $-4.8 \pm 4.6 \mathrm{~mm}$ and $-4.3 \pm 3.3 \mathrm{~mm}$, respectively). Agreement and accuracy of landing zone measurement for each imaging modality compared to implanted device size were studied using adapted Bland-Altman plots as shown in Figure 24.

\section{Discussion}

We reported on a single-center retrospective study of 61 consecutive patients who underwent percutaneous LAA closure. Our study aimed to investigate LAA measurement with three different imaging modalities (TEE, MDCT and LAA angiography) and compare the accuracy of LAA sizing with the implanted device size and study the safety and efficacy of percutaneous LAA closure.

Our study showed high procedural success with only 4 patients (6.6\%) experiencing mild peri-device leakage. Only $4.9 \%$ of cases had in-hospital complications which is in the range of other previous large studies and registries complication rates of 2.2-6.7\%[7,8,5,13-15]. Our center chose a higher acceptable device compression rate of $10-30 \%$ resulting in a higher number of cases with oversizing (54.4\%), based on manufacturer's recommendations[16,7]. However, there was no difference in peri-device leakage between the correct sized group and the oversized group at the 45 to 60-day follow-up assessment which may imply broader safety compression rate than currently recommended.

One of the main findings from our study is that all parameters of LAA measurement including LAA ostial diameter, maximal depth and landing zone diameter are larger with MDCT sizing in comparison with TEE sizing. Landing zone diameter was $1.7 \pm 2.6 \mathrm{~mm}$ larger with MDCT sizing than TEE sizing which may lead to device upsizing in a few cases. Using the final implanted device size as the optimal LAA size, MDCT sizing was closer to the optimal size than TEE sizing with the difference between MDCT sizing and device size of only $-1.7 \pm 2.0 \mathrm{~mm}$ compared to $-4.8 \pm 4.6 \mathrm{~mm}$ for the difference between TEE sizing and optimal device size. Previous studies reported larger discrepancies between MDCT and TEE of up to 2-3 $\mathrm{mm}$ which led to sizing errors of up to $3.4 \%$ of cases[10,9,12,17,18]. We hypothesize that because our center uses a higher compression rate than manufacturer's recommendation, larger device size may correct the smaller landing zone diameter measured by TEE and have similar procedural success as using MDCT sizing. 
Our study has some limitations. We conducted a single center retrospective study resulting in a relatively small number of patients. There were two LAA closure devices with different sizing recommendations and device characteristics. Not all the included patients had MDCT images with only patients in the Omega device group having MDCT sizing. TEE, MDCT and angiography were retrospectively reviewed and measured by investigators who were not? the same group of clinicians who performed the procedure and may have introduced measurement bias.

\section{Conclusion}

MDCT sizing of LAA was more accurate compared to TEE sizing and LAA angiography. Routine implementation of MDCT sizing may improve procedural success with more accurate device size selection. Sizing discrepancies using standard TEE images and LAA angiography may be overcome by increased device size and higher acceptable compression rate.

\section{Declarations}

\section{Funding:}

The study did not receive funding.

\section{Conflict of interest:}

There are no conflicts of interest to declare.

\section{Ethics approval:}

The study obtained approval from the Institutional Review Board, Faculty of Medicine, Chulalongkorn University.

IRB No. 054/63

\section{References}

1. January CT, Wann LS, Alpert JS, Calkins H, Cigarroa JE, Cleveland JC, Jr., Conti JB, Ellinor PT, Ezekowitz MD, Field ME, Murray KT, Sacco RL, Stevenson WG, Tchou PJ, Tracy CM, Yancy CW (2014) 2014 AHA/ACC/HRS guideline for the management of patients with atrial fibrillation: executive summary: a report of the American College of Cardiology/American Heart Association Task Force on practice guidelines and the Heart Rhythm Society. Circulation 130 (23):2071-2104. doi: $10.1161 /$ cir.0000000000000040

2. Kirchhof P, Benussi S, Kotecha D, Ahlsson A, Atar D, Casadei B, Castella M, Diener HC, Heidbuchel H, Hendriks J, Hindricks G, Manolis AS, Oldgren J, Popescu BA, Schotten U, Van Putte B, Vardas P (2016) 2016 ESC Guidelines for the management of atrial fibrillation developed in collaboration with EACTS. European heart journal 37 (38):2893-2962. doi:10.1093/eurheartj/ehw210 
3. January CT, Wann LS, Calkins H, Chen LY, Cigarroa JE, Cleveland JC, Jr., Ellinor PT, Ezekowitz MD, Field ME, Furie KL, Heidenreich PA, Murray KT, Shea JB, Tracy CM, Yancy CW (2019) 2019 AHA/ACC/HRS Focused Update of the 2014 AHA/ACC/HRS Guideline for the Management of Patients With Atrial Fibrillation: A Report of the American College of Cardiology/American Heart Association Task Force on Clinical Practice Guidelines and the Heart Rhythm Society in Collaboration With the Society of Thoracic Surgeons. Circulation 140 (2):e125-e151. doi:10.1161/cir.0000000000000665

4. Holmes DR, Reddy VY, Turi ZG, Doshi SK, Sievert H, Buchbinder M, Mullin CM, Sick P (2009) Percutaneous closure of the left atrial appendage versus warfarin therapy for prevention of stroke in patients with atrial fibrillation: a randomised non-inferiority trial. Lancet (London, England) 374 (9689):534-542. doi:10.1016/s0140-6736(09)61343-x

5. Holmes DR, Jr., Kar S, Price MJ, Whisenant B, Sievert H, Doshi SK, Huber K, Reddy VY (2014) Prospective randomized evaluation of the Watchman Left Atrial Appendage Closure device in patients with atrial fibrillation versus long-term warfarin therapy: the PREVAlL trial. Journal of the American College of Cardiology 64 (1):1-12. doi:10.1016/j.jacc.2014.04.029

6. Vainrib AF, Harb SC, Jaber W, Benenstein RJ, Aizer A, Chinitz LA, Saric M (2018) Left Atrial Appendage Occlusion/Exclusion: Procedural Image Guidance with Transesophageal Echocardiography. Journal of the American Society of Echocardiography : official publication of the American Society of Echocardiography 31 (4):454-474. doi:10.1016/j.echo.2017.09.014

7. Glikson M, Wolff R, Hindricks G, Mandrola J, Camm AJ, Lip GYH, Fauchier L, Betts TR, Lewalter T, Saw J, Tzikas A, Sternik L, Nietlispach F, Berti S, Sievert H, Bertog S, Meier B (2020) EHRA/EAPCI expert consensus statement on catheter-based left atrial appendage occlusion - an update. Eurolntervention : journal of EuroPCR in collaboration with the Working Group on Interventional Cardiology of the European Society of Cardiology 15 (13):1133-1180. doi:10.4244/eijy19m08_01

8. Asmarats L, Rodés-Cabau J (2017) Percutaneous Left Atrial Appendage Closure: Current Devices and Clinical Outcomes. Circulation Cardiovascular interventions 10 (11). doi:10.1161/circinterventions.117.005359

9. Chow DH, Bieliauskas G, Sawaya FJ, Millan-Iturbe O, Kofoed KF, Søndergaard L, De Backer O (2017) A comparative study of different imaging modalities for successful percutaneous left atrial appendage closure. Open heart 4 (2):e000627. doi:10.1136/openhrt-2017-000627

10. Rajwani A, Nelson AJ, Shirazi MG, Disney PJS, Teo KSL, Wong DTL, Young GD, Worthley SG (2017) CT sizing for left atrial appendage closure is associated with favourable outcomes for procedural safety. European heart journal cardiovascular Imaging 18 (12):1361-1368. doi:10.1093/ehjci/jew212

11. Xu B, Betancor J, Sato K, Harb S, Abdur Rehman K, Patel K, Kumar A, Cremer PC, Jaber W, Rodriguez LL, Schoenhagen P, Wazni O (2018) Computed tomography measurement of the left atrial appendage for optimal sizing of the Watchman device. Journal of cardiovascular computed tomography 12 (1):50-55. doi:10.1016/j.jcct.2017.11.012 
12. Saw J, Fahmy P, Spencer R, Prakash R, McLaughlin P, Nicolaou S, Tsang M (2016) Comparing Measurements of CT Angiography, TEE, and Fluoroscopy of the Left Atrial Appendage for Percutaneous Closure. Journal of cardiovascular electrophysiology 27 (4):414-422. doi:10.1111/jce.12909

13. Reddy VY, Doshi SK, Kar S, Gibson DN, Price MJ, Huber K, Horton RP, Buchbinder M, Neuzil P, Gordon NT, Holmes DR, Jr. (2017) 5-Year Outcomes After Left Atrial Appendage Closure: From the PREVAIL and PROTECT AF Trials. Journal of the American College of Cardiology 70 (24):2964-2975. doi:10.1016/j.jacc.2017.10.021

14. Reddy VY, Gibson DN, Kar S, O'Neill W, Doshi SK, Horton RP, Buchbinder M, Gordon NT, Holmes DR (2017) Post-Approval U.S. Experience With Left Atrial Appendage Closure for Stroke Prevention in Atrial Fibrillation. Journal of the American College of Cardiology 69 (3):253-261. doi:10.1016/j.jacc.2016.10.010

15. Boersma LV, Schmidt B, Betts TR, Sievert H, Tamburino C, Teiger E, Pokushalov E, Kische S, Schmitz T, Stein KM, Bergmann MW (2016) Implant success and safety of left atrial appendage closure with the WATCHMAN device: peri-procedural outcomes from the EWOLUTION registry. European heart journal 37 (31):2465-2474. doi:10.1093/eurheartj/ehv730

16. Omega ${ }^{\mathrm{TM}}$ Left Atrial Appendage (LAA) Occluder in Patients With Non-Valvular Atrial Fibrillation Identifier NCT03526471. ClinicalTrials.gov [Internet]. Available via Bethesda (MD): National Library of Medicine (US). 2000 Feb 29. https://ClinicalTrials.gov/show/NCT03526471. Accessed Nov 202019

17. Goitein O, Fink N, Hay I, Di Segni E, Guetta V, Goitein D, Brodov Y, Konen E, Glikson M (2017) Cardiac CT Angiography (CCTA) predicts left atrial appendage occluder device size and procedure outcome. The international journal of cardiovascular imaging 33 (5):739-747. doi:10.1007/s10554-016-1050-6

18. López-Mínguez JR, González-Fernández R, Fernández-Vegas C, Millán-Nuñez V, Fuentes-Cañamero ME, Nogales-Asensio JM, Doncel-Vecino J, Yuste Domínguez M, García Serrano L, Sánchez Quintana D (2014) Comparison of imaging techniques to assess appendage anatomy and measurements for left atrial appendage closure device selection. The Journal of invasive cardiology 26 (9):462-467

\section{Tables}

Table 1: Baseline characteristics of study population $(n=61)$ 


\begin{tabular}{|c|c|c|c|c|}
\hline & Total $n=61$ & Watchman $n=43$ & Omega $n=18$ & $\mathrm{p}$-value \\
\hline Age (years) & $74.0 \pm 8.4$ & $73.6 \pm 8.4$ & $74.9 \pm 8.6$ & 0.578 \\
\hline Age $>65$ years & $51(83.6 \%)$ & $35(81.4 \%)$ & $16(88.9 \%)$ & 0.708 \\
\hline Age $>75$ years & $28(45.9 \%)$ & $19(44.2 \%)$ & $9(50.0 \%)$ & 0.781 \\
\hline \multicolumn{5}{|l|}{ Sex } \\
\hline Male & $35(57.4 \%)$ & $24(55.8 \%)$ & $11(61.1 \%)$ & 0.781 \\
\hline Female & $26(42.6 \%)$ & $19(44.2 \%)$ & $7(38.9 \%)$ & 0.781 \\
\hline Weight (kg) & $64.0 \pm 12.7$ & $64.9 \pm 10.9$ & $62.0 \pm 16.6$ & 0.423 \\
\hline Height (cm) & $161.1 \pm 8.2$ & $161.6 \pm 7.6$ & $159.9 \pm 9.4$ & 0.464 \\
\hline $\mathrm{BMI}\left(\mathrm{kg} / \mathrm{m}^{2}\right)$ & $24.6 \pm 3.9$ & $24.8 \pm 3.6$ & $24.0 \pm 4.5$ & 0.441 \\
\hline $\operatorname{BSA}\left(\mathrm{m}^{2}\right)$ & $1.69 \pm 0.19$ & $1.70 \pm 0.16$ & $1.65 \pm 0.25$ & 0.345 \\
\hline Hypertension & $53(86.9 \%)$ & $37(86.1 \%)$ & $16(88.9 \%)$ & 1.000 \\
\hline Diabetes & $19(31.2 \%)$ & $11(25.6 \%)$ & $8(44.4 \%)$ & 0.225 \\
\hline Stroke/TIA/Thromboembolism & $29(47.5 \%)$ & $24(55.8 \%)$ & $5(27.8 \%)$ & 0.055 \\
\hline Vascular disease & $28(45.9 \%)$ & $19(44.2 \%)$ & $9(50.0 \%)$ & 0.781 \\
\hline Congestive heart failure & $10(16.4 \%)$ & $8(18.6 \%)$ & $2(11.1 \%)$ & 0.708 \\
\hline Abnormal liver function & $3(4.9 \%)$ & $1(2.3 \%)$ & $2(11.1 \%)$ & 0.206 \\
\hline Abnormal renal function & $4(6.6 \%)$ & $4(9.3 \%)$ & $0(0.0 \%)$ & 0.310 \\
\hline Labile INRs & $10(16.4 \%)$ & $4(9.3 \%)$ & $6(33.3 \%)$ & 0.052 \\
\hline Other antithrombotic medications & $23(37.7 \%)$ & $15(34.9 \%)$ & $8(44.4 \%)$ & 0.567 \\
\hline Alcohol use & $1(1.6 \%)$ & $0(0.0 \%)$ & $1(5.6 \%)$ & 0.295 \\
\hline \multicolumn{5}{|l|}{ Previous major bleeding } \\
\hline Intracranial hemorrhage & $16(26.2 \%)$ & $13(30.2 \%)$ & $3(16.7 \%)$ & 0.350 \\
\hline GI bleeding & $8(13.1 \%)$ & $7(16.3 \%)$ & $1(5.6 \%)$ & 0.417 \\
\hline Other bleedings & $12(19.7 \%)$ & $4(9.3 \%)$ & $8(44.4 \%)$ & 0.004 \\
\hline No bleeding & $30(49.2 \%)$ & $21(48.8 \%)$ & $9(50.0 \%)$ & 1.000 \\
\hline CHA2DS2 score & $2.8 \pm 1.4$ & $3.0 \pm 1.4$ & $2.6 \pm 1.5$ & 0.325 \\
\hline CHA2DS2 VASc score & $4.6 \pm 1.8$ & $4.7 \pm 1.9$ & $4.3 \pm 1.9$ & 0.405 \\
\hline HAS-BLED score & $2.6 \pm 1.0$ & $2.6 \pm 1.1$ & $2.8 \pm 1.0$ & 0.452 \\
\hline
\end{tabular}




\begin{tabular}{|lllll|}
\hline & Total $n=61$ & Watchman $n=43$ & Omega $n=18$ & p-value \\
\hline Rhythm & & & & \\
\hline Paroxysmal AF & $30(49.2 \%)$ & $24(55.8 \%)$ & $6(33.3 \%)$ & 0.264 \\
\hline Permanent AF & $31(50.8 \%)$ & $19(44.2 \%)$ & $12(66.7 \%)$ & \\
\hline Oral anticoagulation & & & & \\
\hline On oral anticoagulation & $46(75.4 \%)$ & $30(69.8 \%)$ & $16(88.9 \%)$ & 0.192 \\
\hline Warfarin & $38(62.3 \%)$ & $23(53.5 \%)$ & $15(83.3 \%)$ & 0.042 \\
\hline Apixaban & $3(4.9 \%)$ & $3(7.0 \%)$ & $0(0.0 \%)$ & 0.548 \\
\hline Dabigatran & $4(4.9 \%)$ & $3(7.0 \%)$ & $0(0.0 \%)$ & 0.548 \\
\hline Rivaroxaban & $2(3.3 \%)$ & $1(2.3 \%)$ & $1(5.6 \%)$ & 0.507 \\
\hline No OAC & $15(24.6 \%)$ & $13(30.2 \%)$ & $2(11.1 \%)$ & 0.192 \\
\hline Antiplatelets & & & & \\
\hline ASA & $20(32.8 \%)$ & $12(27.9 \%)$ & $8(44.4 \%)$ & 0.242 \\
\hline Clopidogrel & $10(16.4 \%)$ & $9(20.9 \%)$ & $1(5.6 \%)$ & 0.256 \\
\hline Ticagrelor & $1(1.6 \%)$ & $1(2.3 \%)$ & $0(0.0 \%)$ & 1.000 \\
\hline No antiplatelet and no OAC & $9(14.8 \%)$ & $7(16.3 \%)$ & $2(11.1 \%)$ & 0.713 \\
\hline
\end{tabular}

Table 2: Procedural characteristics and outcomes of study population $(n=61)$ 


\begin{tabular}{|c|c|c|c|c|}
\hline & Total $n=61$ & $\begin{array}{l}\text { Watchman } \\
\mathrm{n}=43\end{array}$ & Omega $n=18$ & $\begin{array}{l}\mathrm{p}- \\
\text { value }\end{array}$ \\
\hline $\begin{array}{l}\text { Median duration of hospital stay } \\
\text { (days) }\end{array}$ & 1 (1 to 2 ) & 2 (1 to 2 ) & 1 (1 to 1$)$ & 0.014 \\
\hline $\begin{array}{l}\text { Mean duration of hospital stay } \\
\text { (days) }\end{array}$ & $4.9 \pm 15.0$ & $6.4 \pm 17.7$ & $1.2 \pm 0.6$ & 0.220 \\
\hline Device size (mm) & $27.0 \pm 3.4$ & $27.8 \pm 3.3$ & $25.0 \pm 2.6$ & 0.002 \\
\hline Number of attempts & $1.7 \pm 1.6$ & $1.6 \pm 1.4$ & $1.9 \pm 1.8$ & 0.449 \\
\hline Change in device size & $7(11.5 \%)$ & $6(14.0 \%)$ & $0(0.0 \%)$ & 0.167 \\
\hline $\begin{array}{l}\text { Local anesthesia with conscious } \\
\text { sedation }\end{array}$ & $61(100 \%)$ & $43(100 \%)$ & $18(100 \%)$ & N/A \\
\hline TEE guide & $61(100 \%)$ & $43(100 \%)$ & $18(100 \%)$ & N/A \\
\hline Procedure time (min) & $51.1 \pm 24.4$ & $52.3 \pm 24.6$ & $48.2 \pm 24.3$ & 0.583 \\
\hline Fluoroscopy time (min) & $7.7 \pm 6.0$ & $7.0 \pm 4.6$ & $9.5 \pm 8.2$ & 0.155 \\
\hline Contrast volume (ml) & $93.7 \pm 38.4$ & $84.6 \pm 34.2$ & $113.3 \pm 40.6$ & 0.004 \\
\hline \multicolumn{5}{|l|}{ Result } \\
\hline Successful without leakage & $57(93.4 \%)$ & $39(90.7 \%)$ & $18(100 \%)$ & 0.310 \\
\hline Successful with mild leakage & $4(6.6 \%)$ & $4(9.4 \%)$ & $0(0.0 \%)$ & \\
\hline Major leakage & $0(0.0 \%)$ & $0(0.0 \%)$ & $0(0.0 \%)$ & \\
\hline Failed & $0(0.0 \%)$ & $0(0.0 \%)$ & $0(0.0 \%)$ & \\
\hline \multicolumn{5}{|l|}{ Immediate Complication } \\
\hline Air embolism & $1(1.6 \%)$ & $1(2.3 \%)$ & $0(0.0 \%)$ & 1.000 \\
\hline Device embolization & $0(0.0 \%)$ & $0(0.0 \%)$ & $0(0.0 \%)$ & N/A \\
\hline Pericardial effusion & $2(3.3 \%)$ & $0(0.0 \%)$ & $2(11.1 \%)$ & 0.084 \\
\hline None & $58(95.1 \%)$ & $42(97.7 \%)$ & $15(88.9 \%)$ & 0.206 \\
\hline \multicolumn{5}{|l|}{$\begin{array}{l}\text { Leakage at } 45-60 \text { days follow-up } \\
\text { TEE }\end{array}$} \\
\hline No leakage & $43(70.5 \%)$ & $28(65.1 \%)$ & 15 (83.3\%) & 0.222 \\
\hline Mild leakage & $16(26.2 \%)$ & $13(30.2 \%)$ & $3(16.7 \%)$ & \\
\hline More than mild leakage & $2(3.3 \%)$ & $2(4.7 \%)$ & $0(0.0 \%)$ & \\
\hline
\end{tabular}




\begin{tabular}{|c|c|c|c|c|}
\hline & Total n=61 & $\begin{array}{l}\text { Watchman } \\
n=43\end{array}$ & Omega $n=18$ & $\begin{array}{l}\mathrm{p}- \\
\text { value }\end{array}$ \\
\hline Pericardial effusion & $1(1.6 \%)$ & $0(0.0 \%)$ & $1(5.6 \%)$ & 0.295 \\
\hline Device related thrombosis & $2(3.3 \%)$ & $1(2.3 \%)$ & $1(5.6 \%)$ & 0.507 \\
\hline LA thrombus & $1(1.6 \%)$ & $1(2.3 \%)$ & $0(0.0 \%)$ & 1.000 \\
\hline Device protrusion & $2(3.3 \%)$ & $2(4.7 \%)$ & $0(0.0 \%)$ & 1.000 \\
\hline \multicolumn{5}{|l|}{ Post procedural medication } \\
\hline Oral anticoagulation & $24(39.3 \%)$ & $24(55.8 \%)$ & $0(0.0 \%)$ & $\begin{array}{l}< \\
0.001\end{array}$ \\
\hline Warfarin & $21(34.4 \%)$ & $21(48.8 \%)$ & $0(0.0 \%)$ & \\
\hline Apixaban & $0(0.0 \%)$ & $0(0.0 \%)$ & $0(0.0 \%)$ & \\
\hline Dabigatran & $3(4.9 \%)$ & $3(7.0 \%)$ & $0(0.0 \%)$ & \\
\hline Rivaroxaban & $0(0.0 \%)$ & $0(0.0 \%)$ & $0(0.0 \%)$ & \\
\hline No oral anticoagulation & $37(60.7 \%)$ & $19(44.2 \%)$ & $18(100 \%)$ & \\
\hline \multicolumn{5}{|l|}{ Antiplatelets } \\
\hline Aspirin & $40(65.6 \%)$ & $22(51.1 \%)$ & $18(100 \%)$ & $\begin{array}{l}< \\
0.001\end{array}$ \\
\hline Clopidogrel & $29(47.5 \%)$ & $12(27.9 \%)$ & $17(94.4 \%)$ & $\begin{array}{l}<.001 \\
0.001\end{array}$ \\
\hline Ticagrelor & $2(3.3 \%)$ & $1(2.3 \%)$ & $1(5.6 \%)$ & 0.507 \\
\hline \multicolumn{5}{|l|}{ Current Medication } \\
\hline Restart OAC & $2(3.3 \%)$ & $1(2.3 \%)$ & $1(5.6 \%)$ & 0.507 \\
\hline Warfarin & $1(1.6 \%)$ & $0(0.0 \%)$ & $1(5.6 \%)$ & \\
\hline Dabigatran & $1(1.6 \%)$ & $1(2.3 \%)$ & $0(0.0 \%)$ & \\
\hline No OAC & $59(96.7 \%)$ & $42(97.7 \%)$ & $17(94.4 \%)$ & \\
\hline \multicolumn{5}{|l|}{ Long-term complication } \\
\hline Stroke & $3(4.9 \%)$ & $3(7.0 \%)$ & $0(0.0 \%)$ & 0.548 \\
\hline Gastrointestinal bleeding & $2(3.3 \%)$ & $2(4.7 \%)$ & $0(0.0 \%)$ & 1.000 \\
\hline Intracranial hemorrhage & $0(0.0 \%)$ & $0(0.0 \%)$ & $0(0.0 \%)$ & N/A \\
\hline Other bleeding & $3(4.9 \%)$ & $3(7.0 \%)$ & $0(0.0 \%)$ & 0.548 \\
\hline Mortality & $5(8.2 \%)$ & $5(11.6 \%)$ & $0(0.0 \%)$ & 0.309 \\
\hline
\end{tabular}




\begin{tabular}{|lllll|}
\hline & Total $\mathrm{n}=61$ & $\begin{array}{l}\text { Watchman } \\
\mathrm{n}=43\end{array}$ & Omega $\mathrm{n}=18$ & $\begin{array}{l}\mathrm{p} \text { - } \\
\text { value }\end{array}$ \\
\hline Cardiovascular mortality & $2(3.3 \%)$ & $2(4.7 \%)$ & $0(0.0 \%)$ & 1.000 \\
\hline Heart failure & $10(16.4 \%)$ & $9(20.9 \%)$ & $1(5.6 \%)$ & 0.256 \\
\hline Myocardial infarction & $4(6.6 \%)$ & $4(9.3 \%)$ & $0(0.0 \%)$ & 0.310 \\
\hline Arrhythmia & $4(6.6 \%)$ & $3(7.0 \%)$ & $1(5.6 \%)$ & 1.000 \\
\hline Device related death & $0(0.0 \%)$ & $0(0.0 \%)$ & $0(0.0 \%)$ & $\mathrm{N} / \mathrm{A}$ \\
\hline $\begin{array}{l}\text { Pericardial effusion required } \\
\text { treatment }\end{array}$ & $1(1.6 \%)$ & $0(0.0 \%)$ & $1(5.6 \%)$ & 0.295 \\
\hline None & $40(65.6 \%)$ & $26(60.5 \%)$ & $14(77.8 \%)$ & 0.246 \\
\hline $\begin{array}{l}\text { Median duration of follow-up } \\
\text { (months) }\end{array}$ & $\begin{array}{l}14.7(5.3 \text { to } \\
45.9)\end{array}$ & $\begin{array}{l}38.0(13.1 \text { to } \\
57.1)\end{array}$ & $\begin{array}{l}8.1(3.8 \text { to } \\
10.5)\end{array}$ & 0.003 \\
\hline
\end{tabular}

Table 3: Severity of peri-device leakage assessed by TEE at 45 to 60 days post-procedure categorized by manufacturer's sizing recommendations $(n=57)$

\begin{tabular}{|lllll|}
\hline & Within manufacturers' recommendation & Oversizing & Undersizing & p-value \\
\hline No leakage & $17(70.8 \%)$ & $21(67.7 \%)$ & $1(50 \%)$ & 0.898 \\
Mild leakage & $6(25 \%)$ & $9(29.0 \%)$ & $1(50 \%)$ & \\
Moderate leakage & $1(4.2 \%)$ & $1(3.2 \%)$ & $0(0 \%)$ & \\
Total & $24(42.1 \%)$ & $31(54.3 \%)$ & $2(3.5 \%)$ & \\
\hline
\end{tabular}

Table 4: Left atrial appendage measurement by different imaging modalities $(n=61)$ 


\begin{tabular}{|c|c|c|c|c|}
\hline & Total $n=61$ & Watchman $n=43$ & Omega $n=18$ & p-value \\
\hline \multicolumn{5}{|l|}{ LAA morphology } \\
\hline Windsock & $40(65.6 \%)$ & $30(69.8 \%)$ & $10(55.6 \%)$ & 0.183 \\
\hline Cactus & $15(24.6 \%)$ & $11(25.6 \%)$ & $4(22.2 \%)$ & \\
\hline Chicken wing & $5(8.2 \%)$ & $2(4.7 \%)$ & $3(16.7 \%)$ & \\
\hline Whaletail & $1(1.6 \%)$ & $0(0.0 \%)$ & $1(5.6 \%)$ & \\
\hline \multicolumn{5}{|l|}{ LAA Thrombus } \\
\hline No & $59(96.7 \%)$ & $43(100 \%)$ & $16(88.9 \%)$ & 0.084 \\
\hline Small thrombus & $2(3.3 \%)$ & $0(0.0 \%)$ & $2(11.1 \%)$ & \\
\hline \multicolumn{5}{|l|}{ Rhythm during TEE } \\
\hline Atrial fibrillation & $39(63.9 \%)$ & $25(64.1 \%)$ & $14(77.8 \%)$ & 0.237 \\
\hline Sinus & $18(29.5 \%)$ & $14(35.9 \%)$ & $4(22.2 \%)$ & \\
\hline \multicolumn{5}{|l|}{ LAA size by TEE measurement } \\
\hline Maximum LAA ostial diameter (mm) & $24.1 \pm 6.1$ & $24.6 \pm 6.3$ & $23.1 \pm 5.8$ & 0.395 \\
\hline Maximum LAA depth (mm) & $38.0 \pm 6.4$ & $37.7 \pm 5.8$ & $38.6 \pm 7.6$ & 0.647 \\
\hline Maximum landing zone diameter $(\mathrm{mm})$ & $22.2 \pm 4.8$ & $22.4 \pm 5.1$ & $21.7 \pm 4.2$ & 0.581 \\
\hline Maximum landing zone depth $(\mathrm{mm})$ & $30.0 \pm 5.5$ & $29.7 \pm 5.0$ & $30.7 \pm 6.5$ & 0.513 \\
\hline \multicolumn{5}{|l|}{ LAA size by angiogram measurement } \\
\hline Maximum LAA ostial diameter (mm) & $22.5 \pm 3.8$ & $22.7 \pm 3.6$ & $22.2 \pm 4.4$ & 0.648 \\
\hline Maximum LAA depth (mm) & $36.7 \pm 6.9$ & $36.2 \pm 5.9$ & $37.9 \pm 9.0$ & 0.373 \\
\hline Maximum landing zone diameter $(\mathrm{mm})$ & $22.7 \pm 3.5$ & $22.8 \pm 2.8$ & $22.3 \pm 4.8$ & 0.573 \\
\hline Maximum landing zone depth (mm) & $32.0 \pm 6.5$ & $31.4 \pm 5.9$ & $33.6 \pm 7.7$ & 0.227 \\
\hline CT available & $18(29.5 \%)$ & $0(0.0 \%)$ & $18(100 \%)$ & $<0.001$ \\
\hline \multicolumn{5}{|l|}{ LAA size by CT measurement } \\
\hline Maximum LAA ostial diameter (mm) & $26.6 \pm 4.4$ & NA & $26.6 \pm 4.4$ & $\mathrm{~N} / \mathrm{A}$ \\
\hline Maximum LAA depth (mm) & $21.7 \pm 3.6$ & NA & $21.7 \pm 3.6$ & $\mathrm{~N} / \mathrm{A}$ \\
\hline Maximum landing zone diameter $(\mathrm{mm})$ & $23.4 \pm 3.9$ & NA & $23.4 \pm 3.9$ & $\mathrm{~N} / \mathrm{A}$ \\
\hline Maximum diameter at $12 \mathrm{~mm}(\mathrm{~mm})$ & $22.3 \pm 4.3$ & NA & $22.3 \pm 4.3$ & N/A \\
\hline Maximum diameter at $15 \mathrm{~mm}(\mathrm{~mm})$ & $23.0 \pm 4.3$ & NA & $23.0 \pm 4.3$ & $\mathrm{~N} / \mathrm{A}$ \\
\hline
\end{tabular}




\begin{tabular}{|lllll|}
\hline & Total $\mathrm{n}=61$ & Watchman $\mathrm{n}=43$ & Omega $\mathrm{n}=18$ & $\mathrm{p}$-value \\
\hline Implanted device size $(\mathrm{mm})$ & $27.0 \pm 3.4$ & $27.8 \pm 3.3$ & $25.0 \pm 2.6$ & 0.002 \\
\hline Within manufacturer's recommendation & & & & \\
\hline Yes & $24(42.1 \%)$ & $8(20.5 \%)$ & $16(88.9 \%)$ & $<0.001$ \\
\hline Oversizing & $31(54.4 \%)$ & $29(74.4 \%)$ & $2(11.1 \%)$ & \\
Undersizing & $2(3.5 \%)$ & $2(5.1 \%)$ & $0(0.0 \%)$ & \\
\hline Compression & & & & \\
\hline \%Compression at TEE $0^{\circ}$ angle & $21.9 \pm 7.1$ & $21.6 \pm 7.5$ & $22.5 \pm 6.1$ & 0.677 \\
\hline \%Compression at TEE $45^{\circ}$ angle & $22.3 \pm 7.2$ & $22.8 \pm 7.4$ & $21.2 \pm 6.6$ & 0.422 \\
\hline \%Compression at TEE $90^{\circ}$ angle & $22.3 \pm 7.7$ & $22.7 \pm 7.7$ & $21.6 \pm 7.8$ & 0.622 \\
\hline \%Compression at TEE $135^{\circ}$ angle & $20.6 \pm 7.4$ & $21.3 \pm 7.0$ & $18.9 \pm 8.2$ & 0.249 \\
\hline Mean \%Compression & $21.8 \pm 5.7$ & $22.2 \pm 5.8$ & $21.0 \pm 5.4$ & 0.474 \\
\hline
\end{tabular}

Table 5: Comparison of LAA size between different imaging modalities

\begin{tabular}{|lllllll|}
\hline & TEE & CT & Angiogram & $\begin{array}{l}\text { p- } \\
\text { value }\end{array}$ & $\begin{array}{l}\text { p-value } \\
\text { CT vs } \\
\text { AEE vs } \\
\text { CT }\end{array}$ & $\begin{array}{l}\text { p-value } \\
\text { AEE vs } \\
\text { Angio }\end{array}$ \\
\hline $\begin{array}{l}\text { Maximum LAA ostial diameter } \\
\text { (mm) }\end{array}$ & $\begin{array}{l}24.1 \pm \\
6.1\end{array}$ & $\begin{array}{l}26.6 \pm \\
4.4\end{array}$ & $22.5 \pm 3.8$ & 0.025 & $<0.001$ & 0.021 \\
\hline Maximum LAA depth (mm) & $\begin{array}{l}38.0 \pm \\
6.4\end{array}$ & $\begin{array}{l}21.7 \pm \\
3.6\end{array}$ & $36.7 \pm 6.9$ & 0.000 & $<0.001$ & 0.128 \\
\hline $\begin{array}{l}\text { Maximum landing zone } \\
\text { diameter (mm) }\end{array}$ & $\begin{array}{l}22.2 \pm \\
4.8\end{array}$ & $\begin{array}{l}23.4 \pm \\
3.9\end{array}$ & $22.7 \pm 3.5$ & 0.015 & 0.112 & 0.298 \\
\hline $\begin{array}{l}\text { Maximum landing zone depth } \\
\text { (mm) }\end{array}$ & $30.0 \pm$ & N/A & $32.0 \pm 6.5$ & N/A & N/A & 0.003 \\
\hline
\end{tabular}

Table 6: Comparison of LAA size and device size by different imaging modalities 


\begin{tabular}{|lllll|}
\hline $\begin{array}{l}\text { LAA landing zone diameter compared with final } \\
\text { implanted device size }\end{array}$ & $\begin{array}{l}\text { Total } \\
\mathrm{n}=61\end{array}$ & $\begin{array}{l}\text { Watchman } \\
\mathrm{n}=43\end{array}$ & $\begin{array}{l}\text { Omega } \\
\mathrm{n}=18\end{array}$ & $\begin{array}{l}\mathrm{p}- \\
\text { value }\end{array}$ \\
$\begin{array}{l}\text { Maximal LZ diameter measured by TEE - Device size } \\
\text { (mm) }\end{array}$ & $\begin{array}{l}-4.8 \pm \\
4.6\end{array}$ & $-5.5 \pm 4.9$ & $-3.3 \pm 3.4$ & 0.095 \\
\hline $\begin{array}{l}\text { Maximal LZ diameter measured by MDCT - Device } \\
\text { size (mm) }\end{array}$ & $\begin{array}{l}-1.7 \pm \\
2.0\end{array}$ & N/A & $-1.7 \pm 2.0$ & N/A \\
$\begin{array}{l}\text { Maximal LZ diameter measured by LAA angiogram - } \\
\text { Device size (mm) }\end{array}$ & $\begin{array}{l}-4.3 \pm \\
3.3\end{array}$ & $-5.0 \pm 2.8$ & $-2.7 \pm 3.7$ & 0.011 \\
\hline
\end{tabular}

\section{Figures}
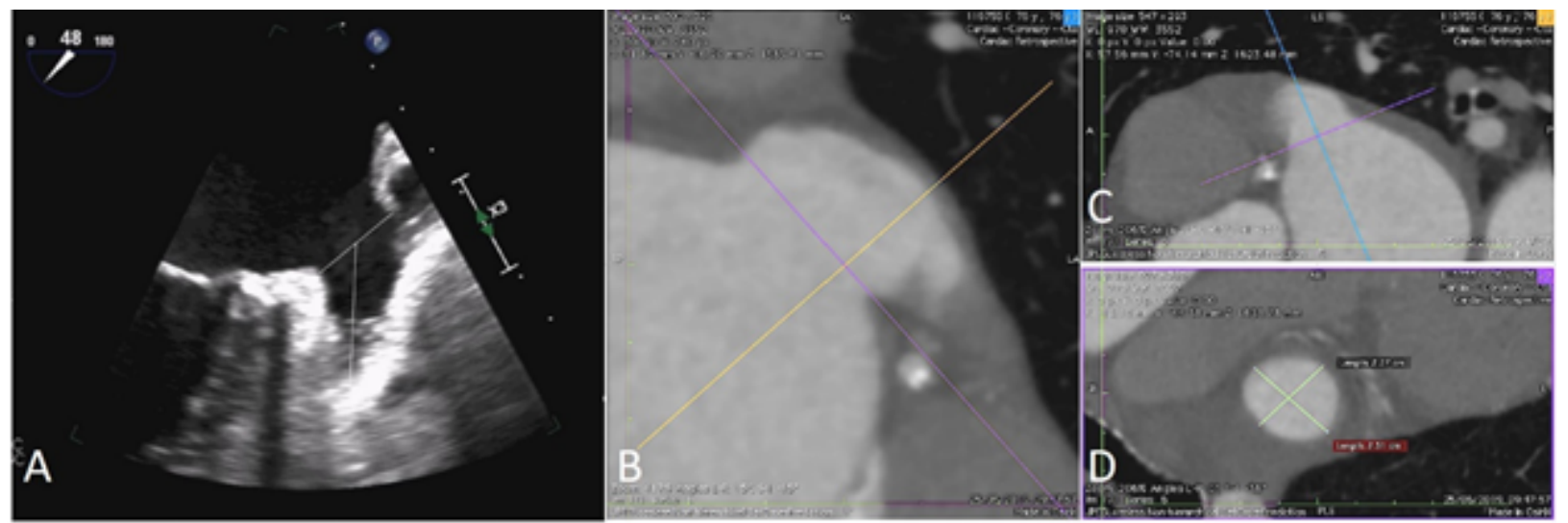

Figure 1

LAA landing zone measurements from transesophageal echocardiography (TEE) image (A) and images from multi-detector CT scan (MDCT) with multi-planar reconstruction (B-D).

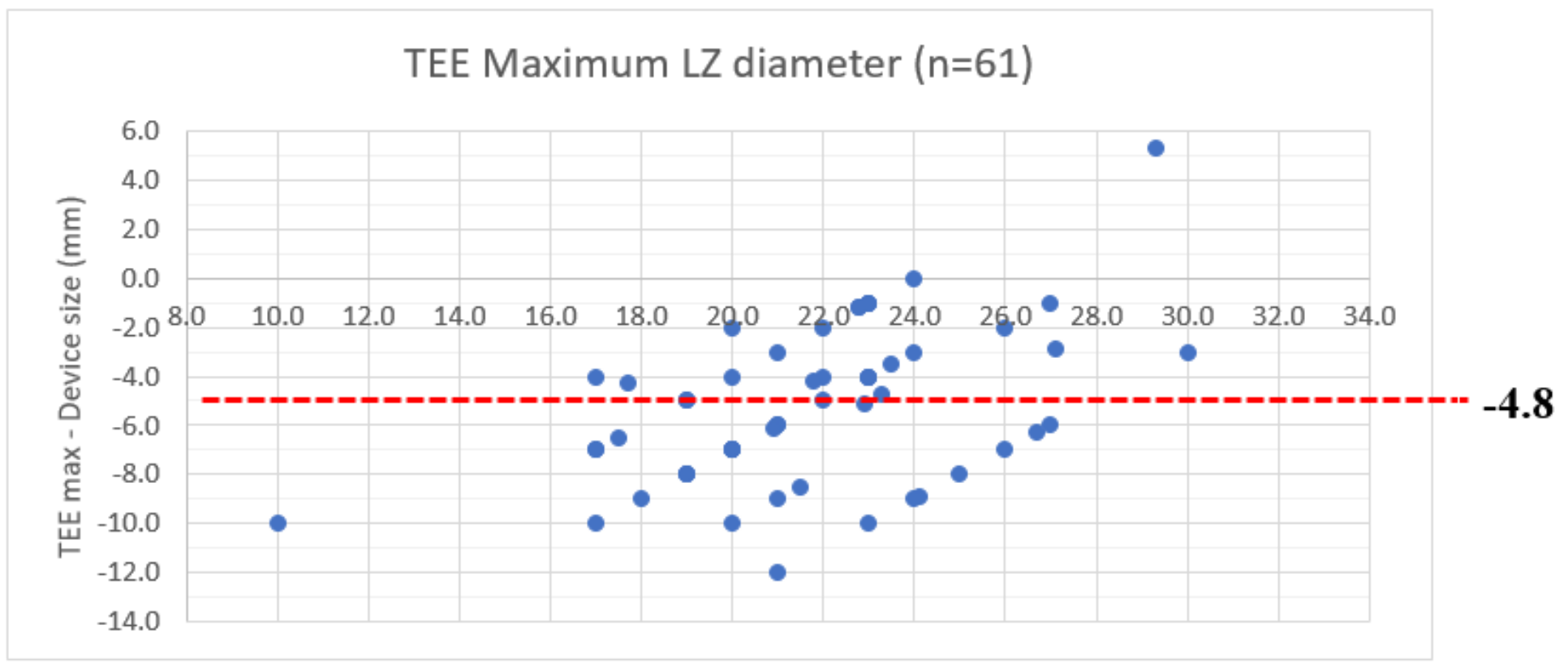

Figure 2 
Adapted Bland-Altman plots for maximal landing zone diameter measured by TEE and final implanted device size. Mean difference between LAA landing zone diameter measured by TEE and final implanted device size: -4.8 [limit of agreement: -6.0;-3.6] $\Delta$ limit of agreement $2.4 \mathrm{~mm}$

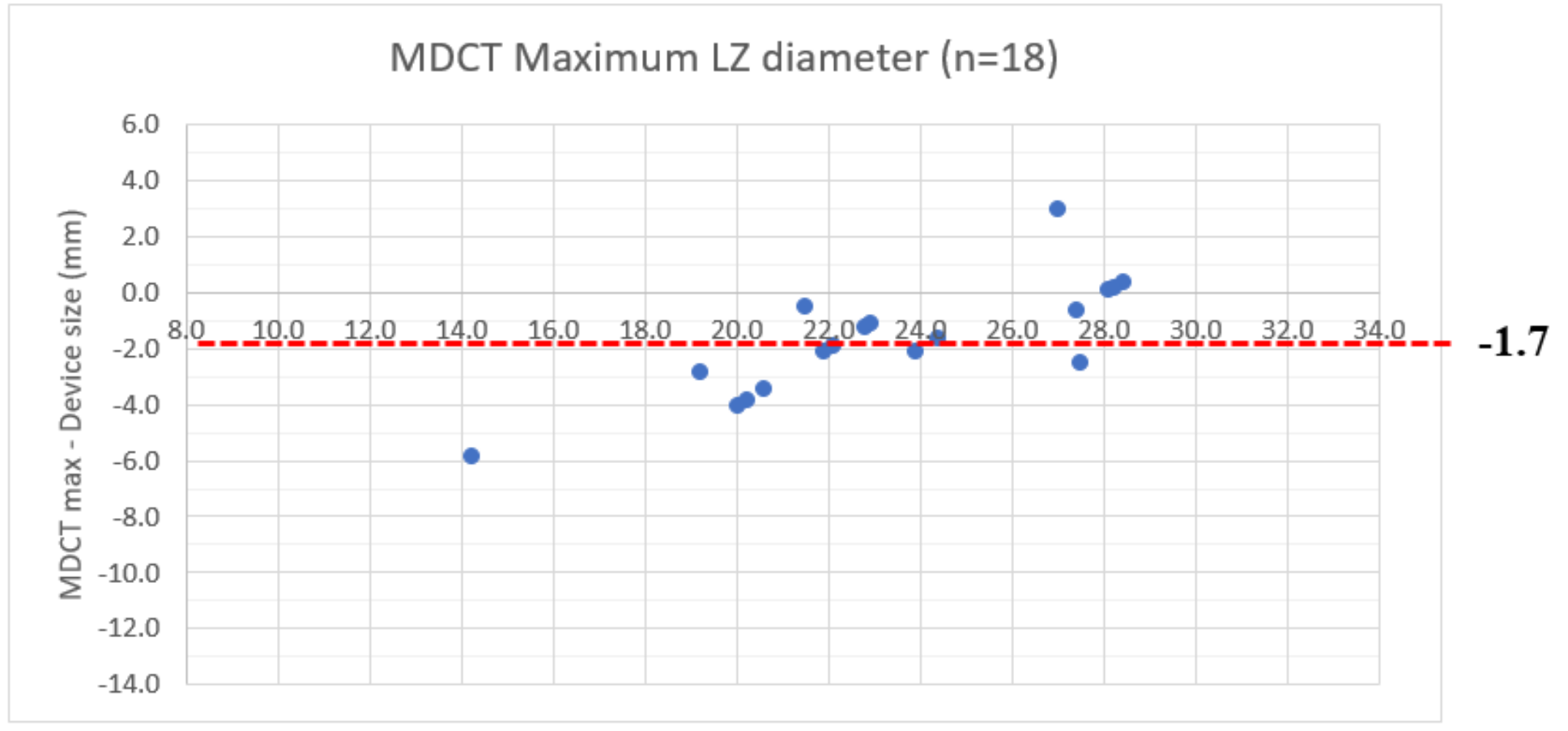

Figure 3

Adapted Bland-Altman plots for maximal landing zone diameter measured by MDCT and final implanted device size. Mean difference between LAA landing zone diameter measured by MDCT and final implanted device size: -1.7 [limit of agreement: $-2.7 ;-0.7$ ] $\Delta$ limit of agreement $2.0 \mathrm{~mm}$

Angiography Maximum LZ diameter $(n=61)$

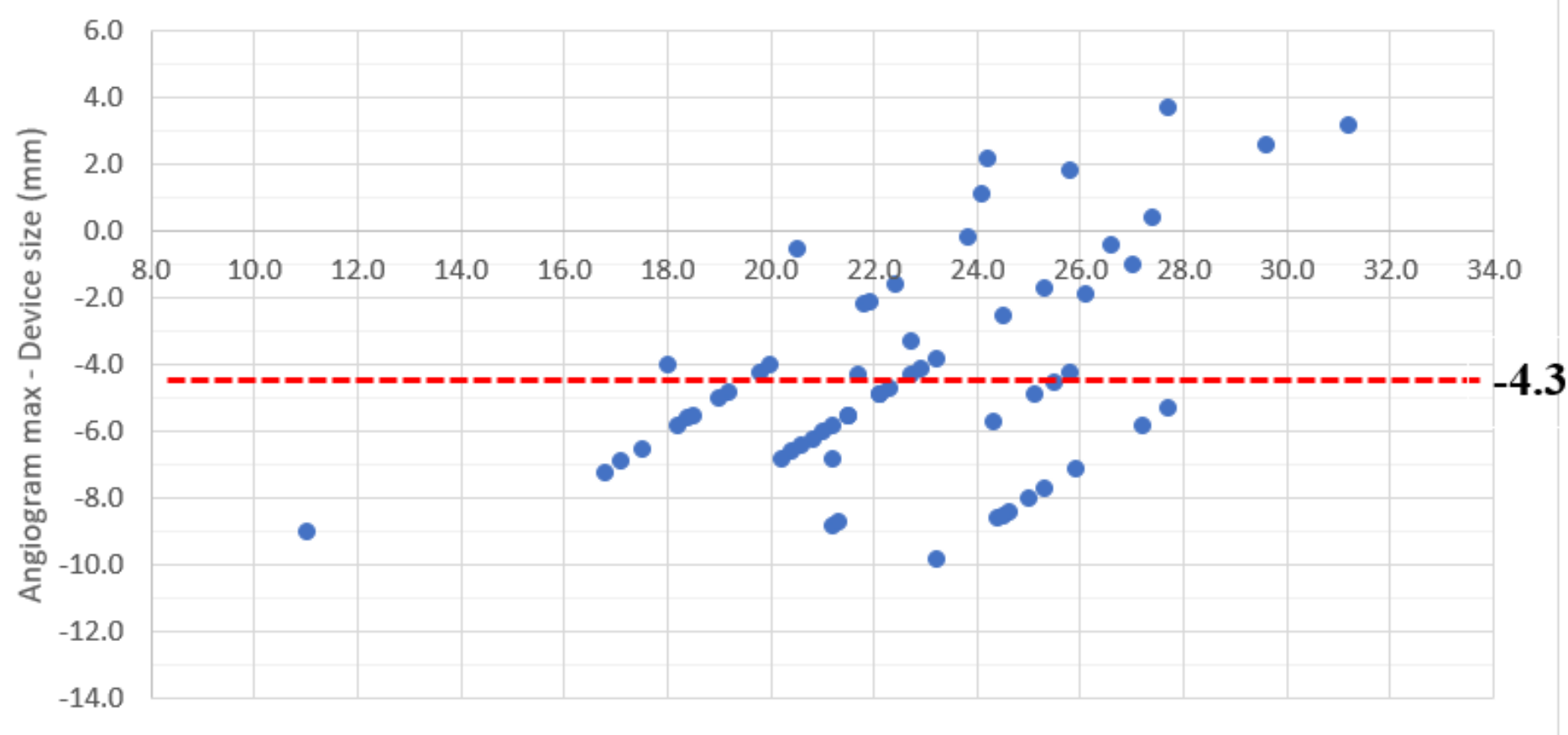


Figure 4

Adapted Bland-Altman plots for maximal landing zone diameter measured by LAA angiography and final implanted device size. Mean difference between LAA landing zone diameter measured by LAA angiogram and final implanted device size: -4.3 [limit of agreement: -5.2; -3.5] $\Delta$ limit of agreement $2.7 \mathrm{~mm}$ 